\title{
Faktor-Faktor yang Berhubungan dengan Tingkat Dismenorea di SMP Negeri di Yogyakarta
}

\author{
Arista Gunawati ${ }^{1}$, Wenny Artanty Nisman ${ }^{2}$ \\ ${ }^{1}$ Mahasiswa Program Studi Ilmu Keperawatan, Fakultas Kedokteran, Universitas Gadjah Mada, Yogyakarta, Indonesia \\ ${ }^{2}$ Staff Pengajar Program Studi IImu Keperawatan, Fakultas Kedokteran, Universitas Gadjah Mada, Yogyakarta, Indonesia \\ Korespondensi: aristagunawati@gmail.com
}

Submisi: 25 Mei 2021; Revisi: 22 Maret 2021; Penerimaan: 29 Maret 2021

\begin{abstract}
Background: The prevalence of incidence primary dysmenorrhea in Indonesia reaches $72,89 \%$. The level of dysmenorrhea varied among teenage girls from mild, moderate, to severe pain. There are various factors affecting the level of dysmenorrhea include age, nutritional status, age of menarche student, age of menarche her mother, the pain menarche, menstrual cycle, duration menstruation, body condition before menstruation, dysmenorrhea frequency, duration dysmenorrhea and disruption of activity.

Objective: To know the factors correlated with level of dysmenorrhea among students in one of Junior High School in Yogyakarta.

Method: This was observational research with cross sectional study and instruments used were questionnaire. This research conducted on Mei 2016. Total population was 195 students with 74 as minimum sample. Sampling technique used was purposive sampling and the study involved 94 students as sample.

Results adn Discussion: Factors associated with the level of dysmenorrhea were pain during menarche, dysmenorrhea frequency and disruption of the activities of the female students in one of the Junior High School in Yogyakarta. Factors not related to the level of dysmenorrhea were age, nutritional status, age of menarche student, age of menarche her mother, menstrual cycle, duration menstruation, body condition prior to menstruation and duration of dysmenorrhea of the female students in one of the Junior High School in Yogyakarta.

Conclusion: Factors associated with level of dysmenorrhea was pain of menarche, dysmenorrhea frequency and disruption of the activities of the female students.
\end{abstract}

Keywords: dysmenorrhea level; menstruation; teenage girl

\section{ABSTRAK}

Latar Belakang: Prevalensi kejadian dismenorea primer di Indonesia mencapai 72,89\%. Tingkat dismenorea pada remaja putri berbeda-beda, mulai dari ringan, sedang dan berat. Terdapat berbagai faktor yang mempengaruhi tingkat dismenorea diantaranya adalah umur, status gizi, umur menarche anak, umur menarche ibu, nyeri menarche, siklus menstruasi, lama menstruasi, kondisi badan sebelum menstruasi, frekuensi dismenorea, lama dismenorea dan terganggunya aktivitas.

Tujuan: Mengetahui faktor-faktor yang berhubungan dengan tingkat dismenorea siswi di salah satu SMP Negeri di Yogyakarta.

Metode: Penelitian observasional dengan pendekatan cross sectional study dengan menggunakan instrumen kuesioner. Penelitian ini dilaksanakan pada bulan Mei 2016. Jumlah populasi adalah 195 siswi dengan teknik purposive sampling sampel minimal 74 siswi, sedangkan sampel yang dapat diambil dan memenuhi kriteria inklusi berjumlah 94 siswi.

Hasil dan Pembahasan: Faktor-faktor yang berhubungan dengan tingkat dismenorea adalah nyeri menarche, frekuensi dismenorea dan terganggunya aktivitas pada siswi di salah satu SMP Negeri di Yogyakarta. Faktor-faktor yang tidak berhubungan dengan tingkat dismenorea adalah umur, status gizi, umur menarche anak, umur menarche ibu, siklus menstruasi, lama menstruasi, kondisi badan sebelum menstruasi, dan lama dismenorea pada siswi disalah satu SMP Negeri di Yogyakarta.

Kesimpulan: Faktor-faktor yang berhubungan dengan tingkat dismenorea adalah nyeri menarche, frekuensi dismenorea dan terganggunya aktivitas.

Kata Kunci: Menstruasi; Remaja Putri; Tingkat Dismenorea 


\section{PENDAHULUAN}

Remaja adalah masa dimana terjadi perubahan dari masa kanak-kanak menuju masa dewasa. ${ }^{1}$ Kesehatan reproduksi pada remaja perempuan masih memerlukan perhatian, terutama dalam hal menghadapi menstruasi. Beberapa remaja ada yang mengalami gangguan menstruasi diantaranya adalah oligomenorea, polimenorea, amenorea, menarche dini, menarche lambat, dismenorea, sindrom pra menstruasi, perdarahan diluar menstruasi dan menoragia. ${ }^{2}$ Berdasarkan hasil penelitian ini yang paling mengganggu adalah dismenorea yaitu 31\% kejadiannya.

Dismenorea yaitu nyeri pada saat menstruasi. Dismenorea ada 2 macam yaitu dismenorea primer dan dismenorea sekunder. Dismenorea primer adalah dismenorea yang tanpa adanya kelainan pada alat genitalia. Dismenorea sekunder adalah dismenorea dengan adanya kelainan pada alat genitalia, seperti adanya tumor, radang, dll. ${ }^{3}$ Menurut hasil penelitian Pusat Informasi dan Konseling Kesehatan Reproduksi Remaja (PIK-KRR) di Indonesia tahun 2009 angka kejadian dismenorea terdiri dari $72,89 \%$ dismenorea primer dan $27,11 \%$ dismenorea sekunder.

Dismenorea sering membuat remaja tidak nyaman, bahkan ada yang sampai mengganggu aktivitas. Karena dismenorea tidak hanya nyeri di perut, tetapi bisa sampai mual muntah, nyeri pinggang, nyeri punggung, berkeringat dingin, nyeri kepala dan pingsan. Beberapa orang yang dismenorea ada yang harus beristirahat dan meninggalkan aktivitasnya selama beberapa jam, atau sampai beberapa hari. ${ }^{4} \mathrm{Hal}$ ini dikarenakan tingkat dismenorea setiap orang berbeda ada yang ringan, sedang dan berat. ${ }^{5}$

Beberapa faktor risiko yang berhubungan dengan beratnya tingkat dismenorea adalah umur yang lebih muda saat terjadinya menarche, siklus menstruasi yang tidak normal, menstruasi yang lama, obesitas, gizi kurang, kurangnya aktivitas fisik, dan riwayat keluarga dengan dismenorea. Perokok dan penggunaan alkohol juga berhubungan dengan terjadinya dismenorea primer. $^{6}$ Hasil penelitian dari Sari et. $a l^{7}$ juga menyatakan bahwa cemas, stres, depresi dapat meningkatkan beratnya tingkat dismenorea.

Menarche adalah menstruasi pertama. Hasil Riset Kesehatan Dasar 8 menunjukkan rata-rata umur menarche di Indonesia adalah 13 tahun dengan umur menarche termuda di bawah 9 tahun dan tertua 20 tahun. Umur menarche ini dipengaruhi oleh faktor internal dan eksternal. Faktor internal yaitu seperti umur menarche ibu (genetik) dan hormon. ${ }^{9}$ Faktor eksternal yaitu asupan gizi, pengetahuan tentang seks, sosial ekonomi, keterpaparan media massa orang dewasa (pornografi), dan gaya hidup. ${ }^{10,11}$ Tetapi dari faktorfaktor tersebut masih terdapat perbedaan hasil. Sehingga peneliti tertarik untuk mengetahui faktor-faktor apa saja yang mempengaruhi tingkat dismenorea dan hubungan karakteristik dismenorea seperti frekuensi dismenorea, lama dismenorea, kondisi badan sebelum menstruasi dan nyeri menarche.

Berdasarkan hasil studi pendahuluan di salah satu SMP Negeri di Yogyakarta bahwa pada tahun ajaran 2014-2015 terdapat 69 kasus dismenorea. Semua siswi kelas 8 dan 9 sudah mengalami menarche, sedangkan kelas 7 masih ada yang belum mengalami menarche. Sehingga peneliti memilih semua siswi kelas 8 sebagai populasi penelitian. Siswi kelas 9 tidak diikutkan dalam penelitian karena guru bimbingan konselingnya memberi himbauan untuk tidak mengganggu karena siswi kelas 9 sudah disibukkan dengan ujian akhir. Berdasarkan hasil wawancara dengan perawat sekolah bahwa tingkat nyeri dismenorea yang dialami siswi bervariasi. Berdasarkan studi pendahuluan tersebut, penelitian ini bertujuan menggali "Faktor-Faktor yang Berhubungan dengan Tingkat Dismenorea Siswi di SMP Negeri di Yogyakarta". 


\section{METODE}

Jenis penelitian ini merupakan jenis penelitian studi observasional (non eksperimental) dengan rancangan cross sectional. Penelitian ini dilaksanakan di salah satu SMP Negeri di Yogyakarta. Subyek penelitiannya adalah siswi kelas 8. Penelitian ini dilaksanakan pada bulan Mei 2016. Pengambilan sampel dengan teknik purposive sampling. Jumlah populasi adalah 195 siswi dengan sampel minimal 74 siswi, sedangkan sampel yang dapat diambil dan memenuhi kriteria inklusi berjumlah 94 siswi. Kriteria inklusinya adalah bersedia di teliti, sudah mengalami menstruasi, pernah mengalami dismenorea dan status gizi atau IMT normal. Kriteria eksklusinya adalah tidak dapat mengingat kapan menarche, memiliki riwayat penyakit ginekologi, mengkonsumsi obat anti nyeri secara rutin, sering merokok dan minum alkohol dan tidak masuk sekolah ketika pengambilan data.

Alat ukur yang digunakan untuk mengukur nyeri menstruasi adalah Numeric Rating Scale (NRS). Alat ini sudah teruji validitas dan reliabilitasnya oleh Hasanah $^{12}$ di Pekanbaru dan memiliki karakteristik responden yang sama dengan penelitian yang akan dilakukan peneliti yaitu responden siswi SMP untuk menguji tingkat dismenorea. Berdasarkan hasil uji yang dilakukan, didapatkan bahwa nilai validitasnya adalah 0,56-0,90 (valid) dan nilai konsistensi interval dengan menggunakan rumus Alpha-Cronbach untuk skala ini adalah 0,907 (reliabel).

Analisis data menggunakan uji korelasi Spearman. Hal ini dikarenakan data yang didapat tidak terdistribusi normal. Data yang dihasilkan termasuk jenis data ordinal.

Penelitian telah memperoleh surat kelayakan etik oleh Komisi etik Fakultas Kedokteran Universitas Gadjah Mada pada tanggal 23 Agustus 2016. Responden yang terlibat telah memberikan kesediaannya dalam mengikuti penelitian dengan mengisi inform consent yang diberikan.

\section{HASIL DAN PEMBAHASAN}

\section{Hasil Penelitian}

Karakteristik Responden

Tabel 1. Karakteristik Responden Siswi di Salah Satu SMP Negeri di Yogyakarta

\begin{tabular}{|c|c|c|}
\hline Karakteristik Responden & $n=94$ & $\%$ \\
\hline \multicolumn{3}{|l|}{ Umur (tahun) } \\
\hline 1. 13 & 25 & 26.6 \\
\hline 2. 14 & 68 & 72.3 \\
\hline 3. 15 & 1 & 1.1 \\
\hline \multicolumn{3}{|l|}{ IMT (Indeks Massa Tubuh) } \\
\hline 1. Normal $(18,5-21,9)$ & 73 & 77,6 \\
\hline $\begin{array}{l}\text { 2. Normal pre obesitas } \\
(22-24,9)\end{array}$ & 21 & 22.3 \\
\hline \multicolumn{3}{|l|}{ Menarche } \\
\hline 1. Cepat (< 12 tahun) & 32 & 34.0 \\
\hline 2. Normal (12-13,9 tahun) & 59 & 62.8 \\
\hline 3. Lambat (>14 tahun) & 3 & 3.2 \\
\hline Menarche rata-rata & 12 (normal) & \\
\hline \multicolumn{3}{|l|}{ Tingkat dismenorea } \\
\hline 1. Ringan (1-3) & 76 & 80,8 \\
\hline 2. Sedang (4-6) & 16 & 17 \\
\hline 3. Berat (7-10) & 2 & 2,1 \\
\hline Tingkat dismenorea rata-rata & 2,2 (ringan) & \\
\hline \multicolumn{3}{|l|}{ Menarche ibu } \\
\hline 1. $<12$ tahun & 4 & 4,2 \\
\hline 2. $12-13,9$ tahun & 18 & 19,1 \\
\hline 3. $>14$ tahun & 72 & 76,5 \\
\hline \multicolumn{3}{|l|}{ Sakit pada saat menarche } \\
\hline 1. Sakit & 27 & 28,7 \\
\hline 2. Tidak & 67 & 71,3 \\
\hline \multicolumn{3}{|l|}{ Siklus mentruasi } \\
\hline 1. $<25$ hari & 13 & 13,8 \\
\hline 2. $25-31$ hari & 79 & 84 \\
\hline 3. $>31$ hari & 2 & 2,1 \\
\hline \multicolumn{3}{|l|}{ Lama menstruasi } \\
\hline 1. $<5$ hari & 4 & 4,2 \\
\hline 2. 5-7 hari & 79 & 84,1 \\
\hline 3. $>7$ hari & 11 & 11,7 \\
\hline \multicolumn{3}{|l|}{ Kondisi badan sebelum mens } \\
\hline 1. biasa & 52 & 55.3 \\
\hline 2. sakit & 42 & 44.7 \\
\hline \multicolumn{3}{|l|}{ frekuensi dismenorea } \\
\hline 1. kadang-kadang & 81 & 86.2 \\
\hline 2. sering & 13 & 13.8 \\
\hline \multicolumn{3}{|l|}{ lama dismenorea } \\
\hline 1. 1-12 jam & 66 & 70.2 \\
\hline 2. 1 - 3 hari & 28 & 29.8 \\
\hline \multicolumn{3}{|l|}{ Mengganggu aktivitas } \\
\hline 1. mengganggu & 49 & 52,1 \\
\hline 2. tidak & 45 & 47,9 \\
\hline
\end{tabular}


Pada tabel diatas diketahui bahwa umur siswi saat ini berkisar antara 13-15 tahun dan sebagian besar berumur 14 tahun sebanyak 68 siswi (72,3\%). IMT siswi dalam rentang normal dibagi menjadi 2 yaitu normal dan normal pre obesitas, sebagian besar IMT pada rentang normal 18,5-21,9 yaitu sebanyak 73 siswi $(77,6 \%)$. Para siswi mengalami menarche berumur 9-14 tahun, sebagian besar siswi menarche pada umur 12-13,9 tahun yaitu 59 siswi (62,8 \%). Tingkat dismenorea sebagian besar siswi pada tingkat ringan (skala 1-3) sebanyak 76 siswi (80,8\%). Umur menarche ibu berkisar antara 9-18 tahun, sebagian besar ibu menarche pada umur $>14$ tahun yaitu 72 orang $(76,5 \%)$. Siklus menstruasi berkisar antara 21-35 hari, sebagian besar siklus menstruasinya 2531 hari sebanyak 79 orang (84 \%). Lama menstruasi antara 3-10 hari, sebagian besar 5-7 hari yaitu sebanyak 79 siswi (84,1\%). Frekuensi dismenorea kebanyakan kadang-kadang 81 siswi (86,2\%). Lama dismenorea rata-rata 1-12 jam sebanyak 66 siswi (70,2 \%). Sebagian besar dismenorea mengganggu aktivitas siswi yaitu sebanyak 49 siswi (52,1\%).

\section{Analisa Faktor-Faktor yang Berhubungan dengan Tingkat Dismenorea}

Tabel 2. Faktor-faktor yang Mempengaruhi Tingkat Dismenorea ( $\mathrm{N}=94)$

\begin{tabular}{|c|c|c|c|c|c|c|c|c|c|}
\hline & & \multicolumn{6}{|c|}{ Tingkat dismenorea } & \multirow{3}{*}{ p } & \multirow{3}{*}{$\mathbf{r}$} \\
\hline & & \multicolumn{2}{|c|}{ Ringan (1-3) } & \multicolumn{2}{|c|}{ Sedang (4-6) } & \multicolumn{2}{|c|}{ Berat (7-9) } & & \\
\hline & & $\mathbf{N}$ & $\%$ & $\mathbf{N}$ & $\%$ & $\mathbf{N}$ & $\%$ & & \\
\hline \multirow{3}{*}{ Umur } & 13 tahun & 20 & 21,2 & 4 & 4,2 & 1 & 1,1 & \multirow{3}{*}{0,802} & \multirow{3}{*}{$-0,026$} \\
\hline & 14 tahun & 55 & 58,5 & 12 & 12,8 & 1 & 1,1 & & \\
\hline & 15 tahun & 1 & 1,1 & 0 & 0 & 0 & 0 & & \\
\hline \multirow{3}{*}{$\begin{array}{l}\text { Umur } \\
\text { menarche }\end{array}$} & Cepat & 24 & 26,5 & 7 & 7,4 & 1 & 1,1 & \multirow{3}{*}{0,626} & \multirow{3}{*}{$-0,051$} \\
\hline & Normal & 51 & 54,2 & 7 & 7,4 & 1 & 1,1 & & \\
\hline & Lambat & 1 & 1,1 & 2 & 2,1 & 0 & 0 & & \\
\hline \multirow[b]{2}{*}{ Status gizi } & $18,5-21,9$ & 58 & 61,7 & 13 & 13,8 & 2 & 2,1 & \multirow[b]{2}{*}{0,288} & \multirow[b]{2}{*}{$-0,111$} \\
\hline & $22-24,9$ & 18 & 19,1 & 3 & 3,2 & 0 & 0 & & \\
\hline \multirow{3}{*}{ Siklus menstruasi } & 21-24 hari & 12 & 12,7 & 1 & 1 & 0 & 0 & \multirow{3}{*}{0,814} & \multirow{3}{*}{0,084} \\
\hline & 25-31 hari & 62 & 66 & 15 & 16 & 2 & 2,1 & & \\
\hline & 31-35 hari & 2 & 2,1 & 0 & 0 & 0 & 0 & & \\
\hline \multirow{3}{*}{ Lama menstruasi } & 3-5 hari & 4 & 4,2 & 0 & 0 & 0 & 0 & \multirow{3}{*}{0,345} & \multirow{3}{*}{$-0,098$} \\
\hline & 5-7 hari & 61 & 64,9 & 16 & 17 & 2 & 2,2 & & \\
\hline & 7-10 hari & 11 & 11,7 & 0 & 0 & 0 & 0 & & \\
\hline \multirow[b]{2}{*}{ Sakit menarche } & tidak & 58 & 61,7 & 7 & 7,4 & 2 & 2,1 & \multirow[b]{2}{*}{0,036} & \multirow[b]{2}{*}{0,217} \\
\hline & sakit & 18 & 19,1 & 9 & 9,5 & 0 & 0 & & \\
\hline \multirow{2}{*}{$\begin{array}{l}\text { Kondisi badan } \\
\text { sebelum menstruasi }\end{array}$} & biasa & 43 & 45,7 & 7 & 7,4 & 2 & 2,1 & \multirow[b]{2}{*}{0,691} & \multirow[b]{2}{*}{0,042} \\
\hline & sakit & 33 & 35,1 & 9 & 9,5 & 0 & 0 & & \\
\hline \multirow[b]{2}{*}{ Frekuensi dismenorea } & Kadang-kadang & 70 & 74,4 & 9 & 9,5 & 2 & 2,1 & \multirow[b]{2}{*}{0,001} & \multirow[b]{2}{*}{0,341} \\
\hline & sering & 6 & 6,4 & 7 & 7,4 & 0 & 0 & & \\
\hline \multirow[b]{2}{*}{ Lama dismenorea } & 1-12 jam & 53 & 56,4 & 11 & 11,7 & 2 & 2,1 & & \\
\hline & 1-3 hari & 23 & 24,4 & 5 & 5,3 & 0 & 0 & 0,792 & $-0,028$ \\
\hline & tidak & 42 & 44,7 & 2 & 2,1 & 1 & 1,1 & & \\
\hline Mengganggu aktivitas & mengganggu & 34 & 36,1 & 14 & 14,9 & 1 & 1,1 & 0,004 & 0,296 \\
\hline
\end{tabular}


Berdasarkan hasil dari tabel diatas didapatkan hasil bahwa tidak ada hubungan antara umur $(p=0,802)$, umur menarche $(p=0,626)$, status gizi $(p=0,288)$, siklus mentruasi $(p=0,814)$, lama menstruasi $(p=0,345)$, kondisi badan sebelum menstruasi $(p=0,691)$ dan lama dismenorea $(p=0,792)$ dengan tingkat dismenorea $(p>0,05)$. Terdapat hubungan antara sakit menarche $(0,036)$, frekuensi dismenorea $(p=0,001)$ dan mengganggu aktivitas $(p=0,004)$ dengan tingkat dismenorea $(p<0,05)$.

\section{Analisa umur menarche ibu dengan umur menarche anak}

Tabel 3. Analisa Umur Menarche Ibu dengan Umur Menarche Anak

\begin{tabular}{|c|c|c|c|c|c|c|c|c|c|c|c|}
\hline & & \multicolumn{6}{|c|}{ Umur menarche anak } & \multirow{2}{*}{\multicolumn{2}{|c|}{ total }} & \multirow{3}{*}{$\mathbf{p}$} & \multirow{3}{*}{$\mathbf{r}$} \\
\hline & & \multicolumn{2}{|c|}{ cepat } & \multicolumn{2}{|c|}{ normal } & \multicolumn{2}{|c|}{ lambat } & & & & \\
\hline & & $\mathbf{N}$ & $\%$ & $\mathbf{N}$ & $\%$ & $\mathbf{N}$ & $\%$ & $\mathbf{N}$ & $\%$ & & \\
\hline \multirow{3}{*}{$\begin{array}{l}\text { Umur } \\
\text { menarche } \\
\text { ibu }\end{array}$} & $<12$ tahun & 4 & 4,2 & 0 & 0 & 0 & 0 & 4 & 4,2 & \multirow[t]{3}{*}{0,016} & \multirow[t]{3}{*}{0,248} \\
\hline & $12-13,9$ tahun & 8 & 8,5 & 10 & 10,6 & 0 & 0 & 18 & 19,1 & & \\
\hline & $>14$ tahun & 20 & 21,3 & 49 & 52,1 & 3 & 3,2 & 72 & 76,6 & & \\
\hline & Total & 32 & 34 & 59 & 62,7 & 3 & 3,2 & 94 & 100 & & \\
\hline
\end{tabular}

Tabel 4 didapatkan hasil bahwa terdapat korelasi antara umur menarche ibu dengan umur menarche anak yaitu $p=0,016(p<0,05)$ dengan nilai korelasi lemah $r=0,248(r<0,4)$. Hal ini menunjukkan bahwa semakin cepat umur menarche ibu maka semakin cepat pula umur menarche anak.

\section{Korelasi umur menarche ibu dengan tingkat dismenorea}

Tabel 4. Korelasi umur menarche ibu dengan tingkat dismenorea anak

\begin{tabular}{|c|c|c|c|c|c|c|c|c|c|c|c|}
\hline & & \multicolumn{6}{|c|}{ Tingkat dismenorea anak } & \multirow{2}{*}{\multicolumn{2}{|c|}{ total }} & \multirow{3}{*}{ p } & \multirow{3}{*}{$\mathbf{r}$} \\
\hline & & \multicolumn{2}{|c|}{ ringan } & \multicolumn{2}{|c|}{ sedang } & \multicolumn{2}{|c|}{ berat } & & & & \\
\hline & & $\mathbf{N}$ & $\%$ & $\mathbf{N}$ & $\%$ & $\mathbf{N}$ & $\%$ & $\mathbf{N}$ & $\%$ & & \\
\hline \multirow{3}{*}{$\begin{array}{l}\text { Umur } \\
\text { menarche } \\
\text { ibu }\end{array}$} & $<12$ tahun & 3 & 3,2 & 0 & 0 & 1 & 1,1 & 4 & 4,2 & \multirow{3}{*}{0,221} & \multirow{3}{*}{0,128} \\
\hline & $12-13,9$ tahun & 17 & 18,1 & 1 & 1,1 & 0 & 0 & 18 & 19,1 & & \\
\hline & $>14$ tahun & 56 & 59,6 & 15 & 15,9 & 1 & 1,1 & 72 & 76,6 & & \\
\hline & Total & 76 & 80,9 & 16 & 17 & 2 & 2,2 & 94 & 100 & & \\
\hline
\end{tabular}

Tabel 4 menunjukkan bahwa tidak ada korelasi antara umur menarche ibu dengan tingkat dismenorea anak yaitu $p=0,221(p>0,05)$ koefisien korelasi 0,128 $(r<0,02)$. Sebagian besar responden umur menarche ibunya $>14$ tahun dengan tingkat dismenorea ringan yaitu sebanyak 56 siswi $(59,6 \%)$.

\section{Hubungan Umur dengan Tingkat Dismenorea}

Penelitian ini menunjukkan bahwa tidak ada hubungan antara umur dengan tingkat dismenorea. Sebagian besar responden berumur 14 tahun dengan tingkat dismenorea ringan.
Menurut Anwar ${ }^{3}$ dismenorea primer muncul beberapa bulan sampai 2-3 tahun setelah menstruasi pertama. Hal ini sesuai dengan penelitian Susanti ${ }^{9}$ bahwa usia terbanyak yang mengalami dismenorea pada rentang usia 13-15 tahun, karena belum sempurnanya sekresi hormonal. Semakin tua umur seseorang, semakin sering orang tersebut mengalami menstruasi dan semakin lebar leher rahim maka sekresi hormon prostaglandin akan semakin berkurang. Selain itu, dismenorea primer nantinya akan hilang dengan makin menurunnya fungsi saraf rahim akibat penuaan. ${ }^{13}$ 
Hasil penelitian ini sesuai dengan hasil penelitian dari Nurhidayati et $a l,{ }^{14}$ bahwa tidak ada hubungan antara umur dengan tingkat dismenorea. Hal ini disebabkan rentang umur responden sempit, sehingga tidak dapat mengetahui hubungannya. Smeltzer ${ }^{15}$ menyebutkan bahwa usia tidak mempengaruhi terhadap berat atau ringannya tingkat nyeri dismenorea, karena pengaruh persepsi nyeri dan toleransi nyeri setiap orang berbeda.

\section{Hubungan Umur Menarche dengan Tingkat Dismenorea}

Berdasarkan hasil penelitian ini dapat diketahui bahwa tidak ada hubungan antara umur menarche dengan tingkat dismenorea. Pada hasil penelitian ini juga dapat diketahui bahwa sebagian besar siswi mempunyai umur menarche normal dengan tingkat dismenorea ringan.

Menurut teori, terdapat hubungan antara umur menarche cepat terhadap kejadian dismenorea primer karena saat menarche, alat reproduksi belum siap untuk mengalami perubahan dan leher rahim masih sempit, sehingga timbul rasa sakit saat menstruasi. ${ }^{16}$ Menarche muda menyebabkan terjadi peningkatan hormon yaitu estrogen dan progesteron. Hormon progesteron yang tinggi dapat meningkatkan sintesis prostaglandin pada endometrium. Prostaglandin yang tinggi mengakibatkan nyeri menstruasi semakin berat. ${ }^{17}$

Hasil penelitian ini berbeda dengan hasil penelitian Utami18 yang menyatakan bahwa tingkat dismenorea yang berat, dialami remaja usia menarche normal. Keparahan dismenorea berhubungan dengan menarche yang terlalu dini. ${ }^{19,20,21}$ Perbedaan hasil penelitian ini dikarenakan terdapat faktor-faktor yang mempengaruhi umur menarche seperti status gizi $^{10}$, genetik ${ }^{11}$, dan lingkungan ${ }^{12}$.

\section{Hubungan Status Gizi dengan Tingkat Dismenorea}

Penelitian ini mendapatkan bahwa tidak ada hubungan antara status gizi dengan tingkat dismenorea. Sebagian besar responden memiliki IMT 18,5-21,9 dengan tingkat dismenorea ringan.
Menurut Widjanarko ${ }^{16}$ bahwa kelebihan berat badan dapat mengakibatkan dismenorea primer karena jaringan lemak yang berlebih dapat mengakibatkan hiperplasi pembuluh darah. Orang dengan status gizi lebih menunjukan peningkatan kadar prostagladin yang berlebih, sehingga memicu terjadinya spasme miometrium. Menurut Dyah ${ }^{22}$ status gizi kurang dapat menyebabkan gangguan menstruasi seperti dismenorea. Hasil penelitian oleh Andriani ${ }^{23}$ menyatakan bahwa semakin rendah IMT, maka tingkat dismenorea akan semakin berat dan sebaliknya. Perbedaan hasil pada penelitian ini dengan penelitian sebelumnya karena pada penelitian ini dipilih responden yang memiliki status gizi normal. Bagi siswi yang IMT nya tidak normal (kurus atau obesitas) tidak diikutkan dalam penelitian ini karena masuk dalam kriteria eksklusi pada saat screening.

\section{Hubungan Siklus Menstruasi dengan Tingkat Dismenorea}

Hasil penelitian ini menunjukkan bahwa tidak ada hubungan antara siklus menstruasi dengan tingkat dismenorea. Sebagian besar mempunyai siklus menstruasi 25-31 hari dengan tingkat dismenorea ringan. Pada penelitian ini dipilih responden yang siklus menstruasinya normal, yaitu sekitar 21-35 hari.

Hasil penelitian ini sesuai dengan penelitian Sophia ${ }^{24}$ bahwa tidak ada hubungan antara siklus menstruasi dengan kejadian dismenorea. Hasil penelitian Utami $^{18}$ juga menyatakan tidak ada hubungan antara siklus menstruasi dengan tingkat dismenorea. hal ini karena siklus menstruasi dipengaruhi juga oleh faktor psikis, yang cenderung pada remaja putri secara emosional tidak stabil. Ketidakstabilan ini mengakibatkan gangguan psikis yang akhirnya menyebabkan gangguan fisiknya, misalnya gangguan haid seperti dismenorea. ${ }^{25}$

\section{Hubungan Lama Menstruasi dengan Tingkat Dismenorea}

Berdasarkan dari hasil penelitian menunjukkan bahwa tidak ada hubungan antara lama menstruasi dengan tingkat dismenorea. Sebagian besar responden mempunyai lama menstruasi 5-7 hari 
dengan tingkat dismenorea ringan. Pada penelitian ini dipilih siswi yang lama menstruasinya normal, yaitu antara 3-10 hari.

Hasil penelitian ini berbeda dengan hasil penelitian dari Purba ${ }^{26}$ yang menyatakan bahwa terdapat hubungan antara lama menstruasi dengan keparahan dismenorea. Lama menstruasi yang $>7$ hari akan mengalami tingkat dismenorea berat. Menurut Shanon ${ }^{27}$ semakin lama menstruasi, maka semakin sering uterus berkontraksi, akibatnya semakin banyak produksi prostaglandin dan menimbulkan rasa nyeri.

\section{Hubungan Nyeri Saat Menarche dengan}

\section{Tingkat Dismenorea}

Berdasarkan hasil penelitian ini menunjukkan bahwa terdapat hubungan antara nyeri pada saat menarche dengan tingkat dismenorea. Sebagian besar responden tidak mengalami nyeri pada saat menarche dengan tingkat dismenorea ringan. Koefisien korelasinya lemah yang berarti responden yang tidak mengalami sakit pada saat menarche maka tingkat dismenoreanya semakin ringan.

Nyeri pada saat menarche dipengaruhi oleh faktor fisiologis dan psikologis. Faktor fisiologis karena tubuh beradaptasi terhadap perubahan hormon belum stabil dan perubahan anatomi belum matang sepenuhnya. Faktor psikologis karena belum siapnya secara mental untuk menghadapi menarche. Perasaan cemas, ketakutan, dapat menimbulkan nyeri pada saat menarche. ${ }^{29}$

\section{Hubungan Kondisi Badan Sebelum Menstruasi dengan Tingkat Dismenorea}

Berdasarkan hasil penelitian menunjukkan bahwa tidak ada hubungan antara kondisi badan sebelum menstruasi dengan tingkat dismenorea. Sebagian besar responden yang kondisi badan sebelum menstruasi biasa mengalami tingkat dismenorea ringan. Pada penelitian ini sebagian kecil responden merasakan sakit sebelum menstruasi. Responden merasakan kondisi yang tidak nyaman seperti nyeri perut dibagian bawah, nyeri pinggang, pusing, mual dan diare ${ }^{30}$.

Berdasarkan hasil penelitian dari Ramadani ${ }^{31}$ sebelum menstruasi, kondisi tubuh akan mengalami perubahan fisiologis maupun psikologis. Kondisi psikologis ditandai dengan perubahan yang cepat dalam suasana hati (misalnya, depresi, iritabilitas, kemarahan, agresi, rnudah menangis, ketegangan, kecemasan). Sedangkan kondisi fisiologis ditandai dengan ketidaknyamanan payudara, nyeri pada perut, sakit kepala,kembung, edema, kelelahan, insomnia).

\section{Hubungan Lama Dismenorea dengan Tingkat Dismenorea}

Dari hasil penelitian ini menunjukkan bahwa tidak ada hubungan antara lama dismenorea dengan tingkat dismenorea. Sebagian besar responden memiliki lama dismenorea 1-12 jam dengan tingkat dismenorea ringan. Hasil penelitian ini sesuai dengan penelitian Novia13 bahwa 56,3\% muncul $<12$ jam sejak mulai menstruasi, 42,3\% muncul 12-24 jam sejak mulai menstruasi dan sisanya 1,4\% muncul >24 jam sejak mulai menstruasi.

\section{Hubungan Frekuensi Dismenorea dengan}

\section{Tingkat Dismenorea}

Hasil penelitian menunjukkan bahwa terdapat hubungan antara frekuensi dismenorea dengan tingkat dismenorea. Koefisien korelasinya menunjukkan bahwa frekuensi dismenorea kadangkadang, semakin ringan tingkat dismenoreanya. Sebagian besar frekuensi dismenorea kadangkadang dengan tingkat dismenorea ringan.

Menurut hasil penelitian dari Nurhidayati ${ }^{14}$ menyatakan bahwa semakin tinggi tingkatan kelas, maka semakin sering pula angka kejadian dismenorea. Tetapi karena dalam penelitian ini tingkatannya sama, maka tidak menjadi faktor pengganggu frekuensi dismenorea. Hasil penelitian ini menunjukkan bahwa dismenorea ringan biasanya frekuensinya kadang-kadang, sedangkan semakin berat tingkat dismenorea frekuensinya lebih sering.

\section{Hubungan Terganggunya Aktivitas dengan Tingkat Dismenorea}

Hasil penelitian menunjukkan bahwa terdapat hubungan antara terganggunya aktivitas dengan tingkat dismenorea. Koefisien korelasinya menunjukkan bahwa semakin ringan tingkat 
dismenoreanya maka aktivitasnya tidak terganggu. Sebagian besar responden yang memiliki tingkat dismenorea ringan, aktivitasnya tidak terganggu.

Hal ini sesuai dengan hasil penelitian dari Kurniawati ${ }^{4}$ bahwa $52 \%$ pelajar tidak dapat melakukan aktivitas harian dengan baik. Hasil penelitian dari Saguni ${ }^{40}$ juga menyatakan bahwa terdapat hubungan antara dismenorea dengan aktivitas belajar. Dismenorea mengganggu akitivitas belajar remaja putri. Fajarini ${ }^{41}$ menyebutkan bahwa ada hubungan antara dismenorea dengan prestasi belajar, remaja putri yang mengalami dismenorea primer lebih sering tidak mengikuti kegiatan belajar, tidak dapat mengikuti ujian dan nilainya lebih rendah.

\section{Hubungan Umur Menarche Ibu dengan Umur Menarche Anak}

Hasil penelitian ini menunjukkan bahwa terdapat hubungan antara umur menarche ibu dengan umur menarche anak. Nilai korelasi menunjukkan bahwa semakin cepat umur menarche ibu maka semakin cepat pula umur menarche anak, begitu juga sebaliknya meskipun nilai korelasi lemah. Sebagian besar responden mempunyai umur menarche normal dengan umur menarche ibu $>14$ tahun.

$\mathrm{Hal}$ ini sesuai dengan penelitian yang dilakukan Putri ${ }^{34}$ bahwa terdapat hubungan genetik (umur menarche ibu) dengan umur menarche pada anak. Hubungan ini diduga berkaitan dengan lokus yang mengatur estrogen yang diwariskan. Pada waktu terjadi kematangan seksual, seorang remaja putri mengikuti menstruasi pertama ibunya. Tetapi pewarisan umur menarche tidak akan sama persis kepada anaknya, tetapi akan bergeser menjadi lebih muda kepada anaknya.

\section{Hubungan Umur Menarche Ibu dengan}

\section{Tingkat Dismenorea}

Hasil penelitian ini menunjukkan bahwa tidak ada hubungan antara umur menarche ibu dengan tingkat dismenorea anak. Sebagian besar responden umur menarche ibunya $>14$ tahun dengan tingkat dismenorea ringan.

Umur menarche ibu berhubungan dengan umur menarche anak, dan umur menarche anak berhubungan dengan tingkat dismenorea. Putrij menyatakan bahwa terdapat hubungan genetik (umur menstruasi pertama ibu) dengan umur menarche pada anak. Tetapi pewarisan umur menarche tidak akan sama persis kepada anaknya, tetapi akan bergeser menjadi lebih muda kepada anaknya. Menurut Widjanarko ${ }^{16}$ umur menarche cepat merupakan faktor risiko dismenorea primer. Hal ini diduga karena saat menarche alat reproduksi belum siap untuk mengalami perubahan dan masih terjadi penyempitan pada leher rahim, maka akan timbul rasa sakit saat menstruasi.

Hasil penelitian ini menunjukkan bahwa tidak ada hubungan antara umur menarche ibu dengan tingkat dismenorea, berbeda dengan teori yang ada. Hal ini dikarenakan banyak faktor yang mempengaruhi umur menarche anak selain umur menarche ibu, seperti status gizi anak, lingkungan dan asupan lemak dan protein hewani.

\section{KESIMPULAN DAN SARAN}

Faktor-faktor yang berhubungan dengan tingkat dismenorea adalah nyeri menarche, frekuensi dismenorea dan terganggunya aktivitas pada siswi di salah satu SMP Negeri di Yogyakarta. Faktorfaktor umur, status gizi, umur menarche anak, umur menarche ibu, siklus menstruasi, lama menstruasi, kondisi badan sebelum menstruasi, dan lama dismenorea tidak berhubungan dengan tingkat dismenorea.

\section{SARAN}

Untuk guru, diharapkan memberi informasi untuk guru mengenai faktor-faktor yang berhubungan dengan tingkat dismenorea. Untuk remaja putri, dengan memberikan informasi terhadap guru diharapkan guru dapat memberikan informasi kepada remaja putri. Sehingga remaja putri dapat mengantisipasi dismenorea dengan menjaga pola hidup sehat. Untuk peneliti selanjutnya, sebaiknya meneliti faktor-faktor yang mempengaruhi tingkat dismenorea lainnya seperti aktivitas fisik, stress, kecemasan dan genetik. Untuk institusi pendidikan, diharapkan pihak institusi pendidikan memberikan penyuluhan tentang kesehatan reproduksi dan masalah menstruasi. 


\section{DAFTAR PUSTAKA}

1. Santrock. J. W. Adolescence: Perkembangan Remaja (edisi keenam). Jakarta: Erlangga; 2003.

2. Sianipar, O; Bunawan, N. C; Almazini, P; Calista, $\mathrm{N}$; Wulandari, P; Rovenska, N; Djuanda, R. E; Irene; Seno, A; Suarthana, E. Prevalensi Gangguan Menstruasi dan Faktor-faktor yang Berhubungan pada Siswi SMU di Kecamatan Pulo Gadung Jakarta Timur. Jurnal Majalah Kedokteran Indonesia. 59(7). Jakarta: Universitas Indonesia; 2009.

3. Anwar, M; A. Bazied; dan R. P. Prabowo.. IImu kandungan. Jakarta: Bina Pustaka Sarwono Prawirahardjo; 2011.

4. Kurniawati, D; Kusumawati, Y. Pengaruh Dismenore Terhadap Aktivitas Pada Siswi Smk. jurnal kesehatan masyarakat. KEMAS 2(6). Semarang: Universitas Negeri Semarang. 9399. 2011. http://journal.unnes.ac.id/index.php/ kemas.

5. Manuaba, I B. G. Kapita Selekta Penatalaksanaan Rutin Obstetri Ginekologi dan KB. Jakarta: EGC; 2008.

6. Lestari, N. M. S. D. Pengaruh Dismenorea Pada Remaja. Seminar Nasional FMIPA UNDIKSHA III Tahun 2013. Jurusan Penjaskesrek, Fakultas Olahraga dan Kesehatan; 2013.

7. Sari, D; Nurdin, A. E; Defrin. Hubungan Stres dengan Kejadian Dismenore Primer pada Mahasiswi Pendidikan Dokter Fakultas Kedokteran Universitas Andalas. Jurnal Kesehatan Andalas. 4(2): 567-580. 2015. http://jurnal. fk.unand.ac.id; 2015.

8. Kementerian Kesehatan. Riset Kesehatan Dasar. Badan Penelitian Dan Pengembangan Kesehatan Kementerian Kesehatan RI; 2010.

9. Susanti, A.V. Faktor Risiko Kejadian Menarche Dini pada Remaja di SMPN 30 Semarang. Journal of Nutrition College. 1(1): 386-407. Universitas Diponegoro. eprints.undip.ac.id/38409/; 2012.

10. Aryati, D. Usia Menarche pada Siswi SD dan SLTP di Kota Bandung. Jurnal Kesehatan Masyarakat Nasional. 2(6): Juni 2008.
11. Padez, C. Social background and age at menarche in Portuguses University students: a note on the secular changes in Potugal. American Journal of Human Biology. May-June 2003; 15(3): 415-27. http://www.ncbi. nlm.nih. gov/pubmed/12704717.

12. Sartika, Shabinaya. Hubungan status gizi dan usia menarche terhadap dismenore primer pada siswi kelas IX SMPN 87 Jakarta tahun 2011. Jakarta: Universitas Pembangunan Nasional Veteran Jakarta; 2011.

13. Novia, I; Puspitasari, N. Faktor risiko yang mempengaruhi kejadian dismenorea. Universitas Airlangga : ilmu kesehatan masyarakat; 2008.

14. Nurhidayati, E., Somantri, I., Suryati, Y. Hubungan Karakteristik Biografi Remaja Dengan Tingkat Nyeri Pada Dismenorea (Studi Di Sma Negeri I Sukaresmi-Cianjur); 2006

15. Smeltzer, S.C., dan Bare, B.G. Buku Ajar Keperawatan Medikal Bedah Brunner \& Suddarth vol. 1. Jakarta: EGC; 2002.

16. Widjanarko, B. Dismenorea Tinjauan Terapi Pada Dismenorea Primer. Majalah Kedokteran Damianus. 5(1): Januari 2006.

17. Yusuf, M. Reproduksi remaja. Jakarta: EGC; 2013.

18. Utami A. N. R; Ansar J; Sidik D. Faktor Yang Berhubungan Dengan Kejadian Dismenorea Pada Remaja Putri Di Sman 1 Kahu Kabupaten Bone. Fakultas Kesehatan Masyarakat. Makassar: UNHAS; 2014.

19. Proctor, M. dan Farquhar, C. Diagnosis And Management Of Dysmenorrhea. British medical journal, 75501134. 2006.

20. Rensburg, E: jansen dan Howard S. Dysmenorrhea. Jakarta: EGC; 2011.

21. Sundell, G., milsom, I and andersch, b. Factors Influencing The Prevalence And Severity Of Dysmenorrhea In Young Women. Bjog : an international journal of obstetrics and gynaecology, 97(7): 588-594. 1990.

22. Dyah, E; Tinah. Hubungan Indeks Masa Tubuh < 20 Dengan Kejadian Dismenore Pada Remaja Putri Di Sma Negeri 3 Sragen . Jurnal Kebidanan, Vol. I, No. $2 ; 2009$. 
23. Andriani, Y. Hubungan Indeks Massa Tubuh, Tingkat Stress, Dan Aktivitas Fisik Dengan Tingkat Dismenore Pada Mahasiswa Diii Kebidanan Semester li Stikes 'Aisyiyah Yogyakarta. Yogyakarta: Program Studi Bidan Pendidik Jenjang Div Sekolah Tinggi Ilmu Kesehatan 'Aisyiyah Yogyakarta; 2015.

24. Sophia, F; Muda, S; Jemadi. Faktor - Faktor Yang Berhubungan Dengan Dismenore Pada Siswi Smk Negeri 10 Medan Tahun 2013 skripsi. Fakultas Kesehatan Masyarakat: Universitas Sumatera Utara; 2013.

25. Liliwati, I et.al. Dysmenorrhea and its Effects on School Activities Among Adolescent Girls in a Rural School in Selangor, Malaysia. Med \& health. 2(1). 42-47; 2007.

26. Purba

27. Shanon, dianne. Dysmenorrhea. (www.mednyu. edu).artikel; 2006.

28. Anurogo D dan Wulandari A. Cara Jitu Mengatasi Nyeri Haid. Yogyakarta: C.V. Andi Offset; 2011.
29. Proverawati; Maisaroh. Menarche Menstruasi Pertama Penuh Makna. Yogyakarta: Nuha Medika; 2009.

30. Rahma. Sindrom Pra Menstruasi. Jakarta: EGC; 2013.

31. Ramadani, Mery. Premenstrual Syndrome. Jurnal Kesehatan Masyarakat. September 2012-Maret 2013. 7(1). Padang: Universitas Andalas; 2013.

32. Saguni, F. C. A., Madianing, A., Masi, G. Hubungan Dismenore dengan Aktivitas Belajar Remaja Putri Di Sma Kristen I Tomohon. ejournal keperawatan (e-Kp). 1(1); Agustus 2013. Program Studi Ilmu Keperawatan Fakultas Kedokteran Universitas Sam Ratulangi Manado.

33. Fajarini, Y. I. Prestasi Belajar Pada Remaja Yang Mengalami Dismenorea Primer. Tesis PSIKM. UGM; 2015.

34. Putri, A. D. Korelasi Status Gizi Dan Stres Dengan Dismenore Padaremaja Putri Kelas X Di Sma Negeri 3 Padang. Padang :Fakultas Keperawatan Universitas Andalas. 2015. 